Original article

Corresponding author:

Laura Carter

Centre for Economic and Social Research on Dementia, Institute for Lifecourse and Society, National University of Ireland, Galway,

Galway, Ireland.

Email: 1.carter1@nuigalway.ie

Tel: 091-524411

\title{
Intensive home care supports, informal care and private provision for people with dementia in Ireland
}

\section{Carter Laura ${ }^{1}$, Stephen O’Neill ${ }^{2}$, Fiona KeoghError! Bookmark not defined., Maria Pierce ${ }^{3}$ and Eamon O'SheaError! Bookmark not defined.}

\footnotetext{
${ }^{1}$ Centre for Economic and Social Research on Dementia, Institute for Lifecourse and Society, National University of Ireland, Galway, Galway, Ireland.

${ }^{2}$ School of Business and Economics, National University of Ireland, Galway, Galway, Ireland.

3 Faculty of Science and Health, Dublin City University, Dublin City University, Glasnevin, Dublin 9, Dublin, Ireland.
} 


\title{
Intensive home care supports, informal care and private provision for people with dementia in Ireland
}

\author{
Abstract \\ Background: This study analyzed the cost of intensive home care packages (IHCPs) for \\ people with dementia living on the boundary of home care and residential care facilities in \\ Ireland. The cost of community-based services and supports, including informal care and \\ private out-of-pocket expenditure, was compared to the cost of public and private \\ residential care.
}

Methods: The study recruited 42 people with dementia and/or their caregivers, who were living on the boundary of home care and residential care, to an in-depth study on the cost of care. The Resource Utilization in Dementia (RUD) scale was used to collect data on the utilization of standard formal care and informal care by people with dementia in receipt of an IHCP. Information on private out-of-pocket expenditure on care was also collected. Unit costs were assigned and community-based care was compared with public and private residential care alternatives.

Results: The average weekly cost of home care, including the IHCP, standard formal community care provision, medications, consumption and housing was estimated at $€ 1,127$. This is lower than the average weekly cost of public long-stay care facilities $(€ 1,526)$ and around the same as for private nursing home fees in the Dublin region 
$(€ 1,149)$. When the opportunity cost valuation of informal care is included, the cost of home care is higher than all types of residential care. Adding private care expenditure further inflates the cost of home care.

Conclusion: Keeping highly dependent people with dementia living at home is not cheap and raises questions about optimal resource allocation on the boundary of home care and residential care. Even with significant public spending on IHCPs, family care costs remain high. So too does private out-of-pocket expenditure on care for some people with dementia.

\section{Key words}

Dementia, boundary of care, resource utilization, care costs. 


\section{Introduction}

Dementia is a neurodegenerative disease that results in the loss of cognitive and social functioning (HSE, 2018). Due to the progressive nature of the condition, the care needs of people with dementia increase throughout the trajectory of the disease, therefore, imposing significant costs on the health and social care system. In 2015, it was estimated that the worldwide yearly cost of dementia was $\$ 818$ billion (Prince et al., 2015). In Ireland, the cost of caring for people with dementia was estimated to be $€ 1.69$ billion per annum (Connolly, Gillespie, O’Shea, Cahill, \& Pierce, 2014).

As the population ages, the predicted increase in the number of people with dementia will have significant budgetary implications (O’Shea, Cahill, \& Pierce, 2017). In recent years, the policies of many developed countries have broadly converged, with each concerned to achieve a movement away from the provision of residential care and towards the greater support of people at home (Challis \& Hughes, 2003; Howe \& Kung, 2003). Such plans have been motivated by a number of considerations, including cost and cost-effectiveness, but the underlying belief is that for older people, including those with complex needs, staying at home for longer is the preferred care option (Department of Health, 2001; Knapp, Chisholm, Astin, Lelliott, \& Audini, 1997).

Therefore, a major issue in all health and social care systems is how to keep very dependent people with dementia who are on the boundary of residential care living at home for longer, rather than being admitted to acute care or expensive long-stay care facilities. Not only is this in line with what people want, but keeping people living at home for longer, or 
postponing admission to hospital or long-stay facilities, may reduce the potential cost of care to the government (O’Shea \& Monaghan, 2016; Wübker et al., 2015).

One of the enduring criticisms of government policy for dependent older people in Ireland is the imbalance in public spending between residential care and community-based care (Donnelly, O'Brien, Begley \& Brennan, 2016; O'Shea, 2017). Thirty years ago, The Years Ahead: A Policy for the Elderly report, highlighted the need for the development and practice of home based care for older people and recommended greater state involvement to support community-based care (Robins, 1988). In 2005, the National Economic and Social Forum called on the then government to spend an additional $€ 500$ million to bring long-term care expenditure up to the OECD average, arguing for a disproportionate spend on home care in the country (NESF, 2005). Historically, even when public resources were relatively plentiful, investment in community-based care has been poor (O'Shea \& Carney, 2016).

Currently, the government is spending more than twice as much on residential care as on community-based care, €962m relative to $€ 408$ million annually (O'Shea, 2017; Health Service Executive, 2018). At present, there is a statutory entitlement to nursing home care in Ireland delivered through the Nursing Home Support Scheme (NHSS), which involves a co-payment arrangement between the state and a contribution from the resident based on a financial assessment of income and assets, including their family home (Wren et al., 2017). However, there is currently no statutory scheme in place for the provision of home care services in the community setting (Browne, 2016). Given the inadequacy of home support services, nursing home admission may be the only option for some people with dementia. It is estimated that there are at least 11,175 people with dementia living at home 
who have a serious functional impairment, 1,876 of whom are chair or bedbound (Pierse, O'Shea \& Carney, 2018). Estimates from the same source suggest 19,530 people with dementia are living in nursing homes in Ireland, the vast majority of whom are likely to have high levels of functional impairment.

In Ireland, the Health Service Executive (HSE) manages the operation of the Irish health service and is responsible for the provision of public health and social care services (HSE, 2019; Wren et al., 2017). The home help service has been the most important communitybased support system for dependent older people living at home. Home help services traditionally consisted of domestic assistance, such as help with cleaning, cooking and personal hygiene. However, since 2012, greater emphasis has been placed on assisting with personal care services (bathing, dressing, etc.). The HSE provided approximately 49,000 older people with home help services in 2017, amounting to 10.6 million home help hours in that year (Timoney, 2018), suggesting that the average number of home help hours was just over 4 hours per week.

Recent innovations in community care in Ireland have focused on the introduction of designated home care packages (HCPs) for older dependent people living at home. The latter are additional supports over and above existing community-based services and are designed to maintain an older person at home for longer through the provision of enhanced home supports and rehabilitation services. They are typically targeted towards people on the margin of residential long-stay care or those who need additional supports following discharge from acute care. The most recent data available suggests that 16,450 older people in Ireland benefited from a home care package during 2016 (Department of Health, 2018). 
The average weekly hours for standard HCPs are 6.5 hours at an average cost of $€ 165$ per week (HSE response to PQ 6498/17).

As part of a process of further development of home care, particularly for people with dementia, the HSE introduced an intensive home care package (IHCP) initiative in 2014. The initiative is closely aligned with a priority action of the National Dementia Strategy Implementation Programme (NDSIP) involving the further development of integrated services for people with dementia, particularly in respect of home supports (Department of Health, 2014; Keogh, Pierce, Neylon, Carter et al., 2018). Intensive home care packages consist of support hours that are greater in range and level than those provided as part of a standard home care package or current community services (Keogh, Pierce, Neylon, Carter et al., 2018; Institute of Public Health (IPH), 2018). IHCPs are designed to keep people with dementia out of acute care and residential care, and to support people with very high levels of need who might otherwise be unable to live at home (Keogh, Pierce, Neylon, Carter et al., 2018).

As part of the investment to support the implementation of the National Dementia Strategy (NDS), a fund of $€ 20.5 \mathrm{~m}$ from Atlantic Philanthropies, the HSE and the Department of Health was made available to deliver IHCPs for individuals with dementia over a three year period. Given the vagaries of the budget system in Ireland, there are no guarantees that IHCPs will be sustained in the longer term, especially since the support of Atlantic Philanthropies for the NDS was a once off contribution to the budgetary process in Ireland (O'Shea \& Carney, 2016). As part of the NDS implementation programme, the HSE commissioned an evaluation of the overall IHCP initiative for people with dementia. This paper is part of the cost evaluation of IHCPs and was conducted through an in-depth study 
of a small sample of IHCP recipients with dementia. The objective is to analyze the cost of IHCPs through an examination of resource utilization of formal, informal and private care for people with dementia living at home on the boundary of community and residential facilities. The analysis facilitates the comparison between the cost of home care and alternative placement in public and private residential care alternatives.

\section{Balance of Care}

The 'Balance of Care' (BoC) approach can be used to identify the types of dependent older people who might equally be cared for at home or in a nursing home, if resources for the former were of sufficient scale and quality (O'Shea \& Monaghan, 2017; Tucker et al., 2016; Challis et al., 2014). A large UK BoC study found that up to half of new care home entrants could be cared for in alternative settings, if adequate resources were made available (Challis et al., 2014). For these case-types, nursing home care could be delayed by 3-12 months by the provision of appropriate community supports. Similarly, for Ireland, O'Shea and Monaghan (2016) highlighted the economic potential of enhanced individualized supports for keeping people with dementia living in their own homes for longer. Their estimates suggest that the weekly average cost of community care for those on the boundary between community and residential care, including formal care provision, new personalized supports, consumption and housing was less than half the cost of potential nursing home care. However, monetizing informal care provision nearly trebled the cost of community-based care.

The resource constraint is crucial in relation to the potential of community-based care to delay or reduce admission into long-stay care. Additional resources are required for community-based care to make a difference to placement decision-making, including 
intensive home care packages. Keeping people at home in the absence of sufficient community-based care is not an easy task (Spijker et al., 2008; Toot, Swinson, Devine, Challis, \& Orrell, 2017; Rothera et al., 2008). Therefore, from an economic perspective, any new investment in IHCPs must be costed and compared to other care alternatives in order to inform the resource allocation process for individuals with dementia living on the boundary of care.

\section{Methods}

\section{Data}

A total of 505 individuals received an IHCP at some point between 2014 and 2017; 297 of those recipients were individuals with dementia who had either a confirmed formal diagnosis of dementia (i.e. from their own GP or another clinician) or had evidence of moderate to severe cognitive impairment based on an assessment by nursing staff or allied therapists. All those approved for dementia-IHCPs were invited to participate in the indepth study between October 2016 and January 2018. Potential participants who responded to the invitation were contacted directly by a member of the research team. A total of 42 persons with dementia and/or their family caregivers, as characterized in Table 1 below, were recruited for this study. Over half of the study sample had dementia that was at a severe stage, $38 \%$ had moderate dementia and $10 \%$ had mild stage dementia (using the Dementia Severity Rating Scale, DSRS). 'Process consent' was adopted to obtain consent from people with dementia to participate in the study (Dewing, 2008). This approach comprises of five parts: background and preparation; establishing a basis for capacity and other abilities; initial consent; ongoing consent and monitoring; and feedback and support. 
Data was collected at baseline and at follow-up. Not everyone completed the baseline questionnaire, hence our resource use focus is primarily on the follow-up dataset which was collected after IHCPs had been in place for some time. This study allows us to take advantage of a novel and comprehensive data set on current resource allocation for individuals with dementia receiving an IHCP who are currently living at home but are also likely to be on the boundary of admission to residential care. In the absence of the IHCP, it is likely, though not certain, that most of these people would be admitted to residential care, such is their level of need relative to conventional and usual home support in Ireland. Ethical approval for the study was obtained through the Royal College of Physicians of Ireland Research Ethics Committee in September 2016.

\section{Table 1. Descriptive analysis}

\begin{tabular}{|l|c|c|}
\hline Variable & In-depth study & Larger study \\
\hline Number of people with dementia & 42 & 297 \\
\hline Age in years: median (interquartile range) & $82.5(74-88)$ & $82(75-87)$ \\
\hline Male & $43 \%$ & $39 \%$ \\
\hline Female & $57 \%$ & $61 \%$ \\
\hline Living with spouse/partner & $57 \%$ & $53 \%$ \\
\hline Living alone & $24 \%$ & $29 \%$ \\
\hline Main informal caregiver: spouse/partner & $48 \%$ & $42 \%$ \\
\hline $\begin{array}{l}\text { Barthel index dependency (0-20): median } \\
\text { (interquartile range) }\end{array}$ & $4.5(2-7)$ & $6(3-10)$ \\
\hline $\begin{array}{l}\text { IHCP support hours per week: median } \\
\text { (interquartile range) }\end{array}$ & $33(30-42)$ & $38(29-48)$ \\
\hline
\end{tabular}


Table 1 presents a comparison of summary statistics on the characteristics of recipients from both the in-depth study and the larger study. With respect to socio-demographic variables, the in-depth study is largely representative of the whole group of people with dementia who received an IHCP. Additional descriptive analysis was carried out on data collected for the in-depth study only, which suggests that it is the spouse/partner and children who provide the majority of informal care to persons with dementia. The average age of carers was 63.0 (interquartile range: 54.5-74) years and the majority of these were female; just over a quarter of carers were engaged in full-time employment. Our findings on caregivers are consistent with a number of previous studies, which confirms the representativeness of our limited sample (O'Shea et al., 2017; Gillespie et al., 2015; Lafferty, Fealy, Downes, \& Drennan 2014; Brennan et al., 2017; Argyle, Downs, \& Tasker, 2010).

The Resource Utilization in Dementia questionnaire was administered face-to-face to persons with dementia and/or their caregivers by a HSE-Genio project leader in order to collect data on formal resource utilization and informal care provision in the previous 30 days. Data on intensive home care support hours was collected from the HSE for all participants in the in-depth study. Information on privately funded care was collected from participants through a schedule of care form which was specially developed to record this information during interviews (Keogh, Pierce, Neylon, O'Neill et al., 2018).

\section{Formal Care Costs}

IHCP costs were calculated by multiplying the number of support hours provided to each individual by the unit cost of a support hour. Under the intensive home care package 
scheme, support hours can be provided by HSE employees and/or HSE approved private care providers. For those individuals who received home support hours from approved private care providers, a unit cost of $€ 22.64$ per hour was applied; this was the average cost of a home care hour based on four approved private care providers in Ireland. For those individuals who received home support hours from both an approved private care provider and directly through the HSE, a unit cost of $€ 23.71$ was applied; this was the average cost of a home care hour based on approved private care providers in Ireland and the HSE salary scale of a home help, including associated non-pay costs.

The cost of standard community-based service provision was calculated by attaching the appropriate unit cost to the relevant averaged resource use across all elements of provision. There is no common, uniform, database that covers unit costs in community-based care in Ireland. Consequently, information on unit costs comes from a variety of mainly Irish data sources (Table 2). Where necessary, unit cost data obtained prior to 2017 were adjusted using an appropriate inflation index (Central Statistics Office, 2018) to reflect costs for 2017. Labour costs were calculated using consolidated salary scales available from the HSE for public-sector employees, with associated non-pay costs estimated according to the methods outlined by the Health Information and Quality Authority (HIQA, 2018). Duration of visit was calculated according to the methods outlined in the Regulatory Impact Analysis guidelines issued by the Department of the Taoiseach (2009).

Table 2. Source of unit cost estimates

\begin{tabular}{|l|l|l|l|}
\hline Resource Activity & Activity & $\begin{array}{l}\text { Unit } \\
\text { Cost }\end{array}$ & Source of Estimates \\
\hline General practice & Per visit & $€ 54$ & Connolly et al., 2014 \\
\hline
\end{tabular}




\begin{tabular}{|c|c|c|c|}
\hline Public health nurse & $\begin{array}{l}\text { Per visit }-30 \\
\text { mins }\end{array}$ & $€ 24$ & $\begin{array}{l}\text { Public health nurse } \\
\text { salary, HSE consolidated } \\
\text { salary scales, } 2018\end{array}$ \\
\hline $\begin{array}{l}\text { Community mental health } \\
\text { nurse }\end{array}$ & $\begin{array}{l}\text { Per visit }-30 \\
\text { mins }\end{array}$ & $€ 25$ & $\begin{array}{l}\text { Community mental health } \\
\text { nurse salary, HSE } \\
\text { consolidated salary } \\
\text { scales, } 2018\end{array}$ \\
\hline Allied health therapies & $\begin{array}{l}\text { Per visit }-30 \\
\text { mins }\end{array}$ & $€ 21$ & $\begin{array}{l}\text { HSE consolidated salary } \\
\text { scales, } 2018\end{array}$ \\
\hline Day care & Per visit & $€ 112$ & $\begin{array}{l}\text { O'Shea \& Monaghan, } \\
2016\end{array}$ \\
\hline Meals on wheels & Per meal & $€ 8$ & $\begin{array}{l}\text { O'Shea \& Monaghan, } \\
2016\end{array}$ \\
\hline Geriatrician (out-patient visit) & Per visit & $€ 148$ & Brick et al., 2015 \\
\hline Psychiatrist (out-patient visit) & Per visit & $€ 148$ & Brick et al., 2015 \\
\hline Neurologist (out-patient visit) & Per visit & $€ 148$ & Brick et al., 2015 \\
\hline $\begin{array}{l}\text { Psychologist (out-patient } \\
\text { visit) }\end{array}$ & $\begin{array}{l}\text { Per visit - one } \\
\text { hour }\end{array}$ & $€ 62$ & $\begin{array}{l}\text { Psychologist salary, HSE } \\
\text { consolidated salary } \\
\text { scales, } 2018\end{array}$ \\
\hline A\&E attendance & Per visit & $€ 271$ & HIPE, 2015 \\
\hline Anti-dementia medication & Per week & $€ 14$ & $\begin{array}{l}\text { HSE PCRS, } 2018 \text { \& } \\
\text { NCPE, 2016, Connolly et } \\
\text { al., } 2014\end{array}$ \\
\hline Anti-psychotic medication & Per week & $€ 28$ & $\begin{array}{l}\text { HSE PCRS, } 2018 \text { \& } \\
\text { NCPE, 2016, Connolly et } \\
\text { al. } 2014\end{array}$ \\
\hline Anti-depressant medication & Per week & $€ 7$ & $\begin{array}{l}\text { HSE PCRS, } 2018 \text { \& } \\
\text { NCPE, 2016, Connolly et } \\
\text { al., } 2014\end{array}$ \\
\hline Acute hospital admission & Per night & $€ 878$ & HIPE, 2017 \\
\hline $\begin{array}{l}\text { Emergency acute hospital } \\
\text { admission }\end{array}$ & Per night & $€ 878$ & HIPE, 2017 \\
\hline
\end{tabular}




\begin{tabular}{|c|c|c|c|}
\hline Psychiatric admission & Per night & $€ 364$ & Connolly et al., 2014 \\
\hline Day hospital & Per visit & $€ 153$ & Green et al., 2014 \\
\hline Home help: non market value & $\begin{array}{l}\text { Per visit - one } \\
\text { hour }\end{array}$ & $€ 28$ & $\begin{array}{l}\text { Home help salary, HSE } \\
\text { consolidated salary } \\
\text { scales, } 2018\end{array}$ \\
\hline $\begin{array}{l}\text { Health care assistant: non } \\
\text { market value }\end{array}$ & $\begin{array}{l}\text { Per visit - one } \\
\text { hour }\end{array}$ & $€ 30$ & $\begin{array}{l}\text { Health care assistant } \\
\text { salary, HSE consolidated } \\
\text { salary scales, } 2018\end{array}$ \\
\hline $\begin{array}{l}\text { Health care assistant: market } \\
\text { value }\end{array}$ & $\begin{array}{l}\text { Per visit - one } \\
\text { hour }\end{array}$ & $€ 22.64$ & $\begin{array}{l}\text { HSE approved private } \\
\text { care providers }\end{array}$ \\
\hline Night duty (non-live) & $\begin{array}{l}\text { Per night - } 9 \\
\text { hours }\end{array}$ & $€ 160$ & $\begin{array}{l}\text { HSE approved private } \\
\text { care providers }\end{array}$ \\
\hline $\begin{array}{l}\text { Home help: non market value } \\
\text { and Health care assistant: } \\
\text { market value }\end{array}$ & $\begin{array}{l}\text { Per visit - one } \\
\text { hour }\end{array}$ & $€ 23.71$ & $\begin{array}{l}\text { Home help salary, HSE } \\
\text { consolidated salary } \\
\text { scales, } 2018 \text { \& HSE } \\
\text { approved private care } \\
\text { providers }\end{array}$ \\
\hline $\begin{array}{l}\text { Opportunity cost method: } \\
\text { caregivers in employment }\end{array}$ & Per hour & $€ 22.34$ & $\begin{array}{l}\text { Average Hourly } \\
\text { Earnings, Q2 2017, CSO }\end{array}$ \\
\hline $\begin{array}{l}\text { Opportunity cost method: } \\
\text { caregivers not in employment }\end{array}$ & Per hour & $€ 5.58$ & $\begin{array}{l}\text { Leisure time: }(25 \% \text { of } \\
\text { Average Hourly } \\
\text { Earnings) }\end{array}$ \\
\hline Public nursing home & Per week & $€ 1,526$ & HSE, 2018 \\
\hline $\begin{array}{l}\text { Private nursing home - Dublin } \\
\text { area }\end{array}$ & Per week & $€ 1,149$ & HSE, 2018 \\
\hline $\begin{array}{l}\text { Private nursing home - rest of } \\
\text { country }\end{array}$ & Per week & $€ 909$ & HSE, 2018 \\
\hline Personal consumption & Per week & $€ 144$ & $\begin{array}{l}\text { O'Shea \& Monaghan, } \\
2017\end{array}$ \\
\hline Capital & Per week & $€ 92.61$ & $\begin{array}{l}\text { O'Shea \& Monaghan, } \\
2017\end{array}$ \\
\hline
\end{tabular}


Standard public and private out-patient visit costs were sourced from Brick et al. (2015), the average of both costs were calculated and adjusted to 2017 prices using an appropriate inflation index. A unit cost of $€ 271$ was applied to an A\&E attendance; this estimate was sourced from the Hospital In-Patient Enquiry dataset and was adjusted to 2017 prices (HIPE, 2015). The cost of a psychologist visit was calculated using the consolidated salary scales available from the HSE for public-sector employees, with associated non-pay costs estimated according to the methods outlined by HIQA (2018). A unit cost of $€ 878$, which is the average cost across all nights in all hospitals and in all types of in-patient cases, was applied to acute hospital admission and emergency hospital admission (HIPE, 2017). A unit cost of $€ 153$ per day was applied to day hospital admission; this cost was sourced from UK data generated by the Personal Social Services Research Unit (PSSRU). CPI data from the origin country and the purchasing power parity index was used to convert the unit cost to local currency (Green et al., 2014; HIQA, 2018; ONS, 2018; OECD, 2018).

Information was collected on the use of anti-dementia, anti-psychotic and anti-depressant drugs by people with dementia in the study. For people on medication, it was assumed that they were taking the most commonly-used drug: Memantine for dementia; Risperidone for psychosis; and Citalopram for depression. The unit costs reflect normal dosage levels taken from the Monthly Index of Medical Specialities (MIMS), adjusted to 2017 prices using an appropriate inflation index.

\section{Private Care Costs}

A unit cost of $€ 22.64$ per hour was applied to private expenditure on care, based on the average cost of a private out-of-pocket care hour across various HSE approved providers in Ireland. An average nightly rate of $€ 160$ was applied to instances where individuals 
purchased care from private providers at night. No data is available on the types of services purchased out-of-pocket from private providers. It is likely that private out-of-pocket care consists mainly of more of the same type of home care hours available through IHCPs, perhaps delivered outside of normal business hours, whereby, the focus of care remains largely on the provision of essential domestic and personal care assistance (such as cleaning, cooking, bathing and dressing). Future work will be necessary to tease out what people spend on private care, for what purpose and at what times.

\section{Informal Care Costs}

Informal care inputs were estimated from data provided by family carers on the total hours of informal support provided to the person with dementia in an average day in respect of each type of support: activities of daily living; instrumental activities of daily living; and supervision. The labour force participation status was available for the carers of individuals with dementia; information was also available on whether people gave up paid work entirely or reduced their hours of paid work in order to care. An opportunity cost methodology was used to measure the baseline cost of informal care (Gillespie et al., 2015). The opportunity cost of time for caregivers categorized as having given up paid work time to care is valued at $€ 22.34$ per hour, which is the average hourly wage across all industrial sectors in Ireland in 2017 (Central Statistics Office, 2017). For those categorized as retired

or not available for work, the opportunity cost of time was valued at a percentage (25\%) of the average hourly wage, equating to $€ 5.58$ per hour (CSO, 2018).

\section{Personal Consumption Costs}


People living in their own homes in the community expend resources on the personal consumption of items such as food, fuel, light and household maintenance. If those identified as being on the margins of residential care were admitted to residential care, these costs would be included as part of the direct costs of care by the institution. Wübker et al. (2015) suggest that the exclusion of personal consumption for people living in their own homes would diminish some of the differences between community care and residential care costs, as this consumption could amount to 15 per cent or more of nursing home outlays. Personal consumption costs must, therefore, be calculated when comparing costs between the two settings. Weekly personal expenditure for people living at home in the community is $€ 144$, based on the Household Budget Survey 2010 (most recently available) estimates of expenditures of a retired household, inflated to 2017 prices using the CPI (Central Statistics Office, 2018).

\section{Housing Costs}

Capital costs are normally included in the pricing structure of private nursing homes. Hence the cost of housing for people with dementia living in the community must also be calculated when making comparisons between the cost of home care and residential care. The two components of capital cost are the opportunity cost of keeping the capital item another year, in this case the house, and the depreciation over time of the asset itself. One method of valuing major capital costs is to calculate the equivalent annual cost by annuitizing the initial capital outlay over the useful life of the asset itself. In calculating the opportunity cost of housing in this study, the current average price of housing is used to determine the replacement value of the house (Lyons, 2018). The analysis assumes a zero per cent discount rate to calculate the equivalent annual housing cost over a 50 year period, 
implying that the increasing value of the house is offset by depreciation over the lifetime of the asset. The cost of capital for an individual living in the community per week is estimated at $€ 92.61$.

\section{Nursing Home Costs}

In order to compare the cost of care for people with dementia had they been institutionalized rather than cared for at home through the delivery of IHCPs, it was necessary to calculate the average cost of public long-stay facilities in Ireland, private nursing homes in the Dublin area and private nursing homes in the rest of the country, given that the sample of IHCP recipients in the study are distributed across the country. Public and private long-stay cost estimates are based on the average cost of agreed prices available from the HSE under the Nursing Home Support Scheme. Average weekly costs were $€ 1,526$ in a public long-stay facility, $€ 1,149$ for private nursing homes in Dublin and $€ 909$ for nursing homes in the rest of the country (HSE, 2018).

\section{Results}

\section{Resource Use}

Resource utilization among people with dementia is presented below in Table 3. The average number of additional support hours provided through the HSE-Genio Dementia Programme to people with dementia and their informal carers was 34 hours per week (ranging from 13 hours to 56 hours per week). In general, despite a relatively high risk of institutionalization, a large number of participants in the study were not in receipt of standard community-based formal provision. The most frequently used standard services 
include public health nurse visits (61\%), GP visits (51\%), day care (28\%) and occupational therapy (21\%), with a low proportion of individuals receiving community mental health nurse visits (8\%) and social work visits (5\%). The overall picture is one of scarcity in regard to standard public community-based care provision for people with dementia living at home in Ireland.

Resource utilization for out-patient and in-patient visits among people with dementia is also presented in Table 3. Psychiatrist (13\%) and geriatrician (10\%) visits were the most commonly used out-patient service for people with dementia living in the community. Only, 5\% of participants experienced an in-patient acute hospital admission in the last month, while only $3 \%$ had an emergency admission to an acute hospital. It should be noted, however, that one person had spent all of the last 30 days in acute care. Only one other person was reported as having been admitted to hospital, but no data was available on their length of stay. We assumed a length of stay of 12 days for this person, based on previous findings from a generic study on hospital admissions and discharges for people with dementia by Connolly and O'Shea (2015). Just over half (56\%) of people with dementia living in the community were prescribed an anti-dementia drug in the last 30 days (Table 3). A smaller proportion of individuals were prescribed anti-depressant medication (33\%) and anti-psychotic medication (27\%).

In $35 \%$ of cases, private out-of-pocket care hours were purchased in order to supplement IHCP support and standard public care for individuals with dementia living in the community setting. An average of 19 hours of private care was bought per week. Not everyone purchased private care, as is clear from the range of the data ( 0 hours to 168 hours per week). On average, carers of people with dementia reported providing 80 hours of 
informal care per week (ranging from 2 hours to 133 per week), or just over 11 hours per day. Even with IHCP provision, there is a considerable reliance on families to support people with dementia in Ireland.

\section{Cost of Home Care}

Table 3 also shows the average weekly costs of care for people with dementia. The average cost of support hours provided through the HSE-Genio Dementia Programme to people with dementia and their informal carers was $€ 774$ per week. The variation in provision is evident with weekly costs ranging between $€ 294$ and $€ 1,268$. The total average weekly cost of standard primary and community care for people with dementia per week was €97.81, almost $77 \%$ of which was accounted for by day-care activity. This was followed by public health nurse visits which accounted for approximately $8 \%$ of the total average cost. Allied health therapies (i.e. physiotherapist, occupational therapist etc.) contributed approximately only $5 \%$ of the overall average cost.

The average costs of out-patient visits per person living in the community setting are also presented in Table 3. Visiting rates were very low overall, for example, only one person attended a psychologist, resulting in average costs of aggregate out-patient visits in the community of only $€ 11.58$ per week. With regard to in-patient care, only two people incurred costs, but one of them spent the previous 30 days in hospital, accounting for $71 \%$ of the entire acute hospital admission costs. The total average weekly cost of medications was $€ 17.80$, of which $44 \%$ is accounted for anti-dementia drugs.

With regard to private out-of-pocket home care hours, the average cost was $€ 391$ (range $€ 0$ - $€ 3,497)$ per week. Some people did not purchase any private care, while others bought 
significant amounts. Informal care costs in the community setting were valued using an opportunity cost methodology, the average cost of informal care was estimated to be $€ 593$ $(€ 33-€ 1,354)$ per week. The average weekly capital cost of housing for people with dementia living in the community was $€ 93$. Over a one week period, the average estimated cost of personal consumption was $€ 144$.

Table 3. Resource utilization and costs of care among people with dementia

\begin{tabular}{|l|c|c|}
\hline \multicolumn{1}{|c|}{ Activity } & Resource Utilization, n (\%) & Average cost per week, $\boldsymbol{\epsilon}$ \\
\hline $\begin{array}{l}\text { Intensive Home Care } \\
\text { Package }\end{array}$ & $42(100)$ & $€ 774.18$ \\
\hline $\begin{array}{l}\text { Primary and Community } \\
\text { Care }\end{array}$ & & \\
\hline GP & $20(51)$ & $€ 7.11$ \\
\hline Nursing & & $€ 7.66$ \\
\hline Public Health Nurse & $23(61)$ & $€ 0.63$ \\
\hline $\begin{array}{l}\text { Community Mental Health } \\
\text { Nurse }\end{array}$ & $3(8)$ & $€ 0.88$ \\
\hline Allied Health Therapies & $4(10)$ & $€ 1.26$ \\
\hline Physiotherapist & $8(21)$ & $€ 0.63$ \\
\hline Occupational Therapy & $5(13)$ & $€ 0.75$ \\
\hline $\begin{array}{l}\text { Speech and Language } \\
\text { Therapy visit }\end{array}$ & $6(15)$ & $€ 0.38$ \\
\hline Chiropodist & $2(5)$ & $€ 1.13$ \\
\hline Social Worker & $8(21)$ & \\
\hline Other Health Professional & & \\
\hline Services & & \\
\hline & & \\
\hline
\end{tabular}




\begin{tabular}{|l|c|c|}
\hline Day care & $11(28)$ & $€ 75.05$ \\
\hline Meals on wheels & $2(5)$ & $€ 2.33$ \\
\hline Out-patient visits & $4(10)$ & $€ 3.54$ \\
\hline Geriatrician & $5(13)$ & $€ 4.43$ \\
\hline Psychiatrist & $0(0)$ & $€ 0.00$ \\
\hline Neurologist & $1(3)$ & $€ 0.37$ \\
\hline Psychologist & $2(5)$ & $€ 3.24$ \\
\hline A\&E attendance & $2(5)$ & $€ 220.63$ \\
\hline In-patient visits & $1(3)$ & $€ 5.25$ \\
\hline Acute hospital admission & $14(35)$ & $€ 0.00$ \\
\hline $\begin{array}{l}\text { Emergency admission to } \\
\text { acute hospital }\end{array}$ & $38(100)$ & $€ 1.79$ \\
\hline Psychiatric hospital & $2(5)$ & $€ 390.63$ \\
\hline Day hospital & $10(27)$ & $€ 593.34$ \\
\hline Prescribed medication & $13(33)$ & $€ 7.90$ \\
\hline Anti-dementia medication & & $€ 7.57$ \\
\hline Anti-psychotic medication & & \\
\hline $\begin{array}{l}\text { Anti-depressant } \\
\text { medication }\end{array}$ & & \\
\hline Private care & & \\
\hline Informal care & & \\
\hline
\end{tabular}

Note: Not everyone who received an intensive home care package responded to each subsequent resource use question. The percentage value reflects actual respondents for each item of resource use.

Table 4 shows the overall average care costs for people with dementia living in the community setting. The estimated average cost of home care for a person with dementia, 
which includes IHCP hours, primary and community care, medications, consumption and housing is $€ 1,127$ per week. Costs rise to $€ 1,720$ per week when informal costs using an opportunity cost methodology are included and rise further to $€ 2,111$ per week when private out-of-pocket care costs are taken into account. The average cost per week for home care when all care costs are included (i.e. adding in-patient and out-patient costs) is $€ 2,351$. On average, informal care and private care account for $42 \%$ of overall care costs for people with dementia living in a community setting and just under half the cost of care if in-patient and out-patient costs are excluded.

Table 4. Overall care costs for people with dementia

\begin{tabular}{|l|c|c|}
\hline \multicolumn{1}{|c|}{ Activity } & Average costs per week, $€$ & \% of overall cost of care \\
\hline $\begin{array}{l}\text { Intensive home care } \\
\text { package }\end{array}$ & $€ 774$ & 33 \\
\hline $\begin{array}{l}\text { Primary and } \\
\text { community care }\end{array}$ & $€ 98$ & 4 \\
\hline Out-patient visits & $€ 12$ & 1 \\
\hline In-patient visits & $€ 228$ & 17 \\
\hline Medications & $€ 391$ & 25 \\
\hline Private care & $€ 593$ & 100 \\
\hline $\begin{array}{l}\text { Informal care } \\
\text { (opportunity cost } \\
\text { method) }\end{array}$ & $€ 144$ & 6 \\
\hline Capital & $€ 2,351$ & 6 \\
\hline Personal consumption & & \\
\hline All & $€ 93$ & 17 \\
\hline
\end{tabular}

Note: Numbers have been rounded. 
We are interested in comparing the potential cost of care for people with dementia if they had been institutionalized rather than cared for at home in the community. Comparing costs in this way is not straightforward, given the often complex case mix in long-stay facilities associated with different levels of dependency and need among residents with dementia. The use of average cost for residential care is, therefore, not ideal, but it is the only figure available to us, as marginal costs are not routinely published, and, in any case, are not always easy to compute. If the comparison is only with IHCP support hours, primary and community care, medications, consumption and housing, the average home care cost of $€ 1,127$ per week is almost comparable to the average cost of a private nursing home in the Dublin area, which costs $€ 1,149$, on average, per week. When compared to the average cost of a public long-stay facility (€1,526 per week), there is a cost saving of $€ 399$ per week. However, when informal care costs are included, community care is more expensive than any type of residential care for people with dementia in Ireland.

\section{Sensitivity Analysis}

The impact of uncertainty in relation to costs was explored using sensitivity analysis. In order to assess variation in the average weekly cost of IHCPs and private out-of-pocket expenditure on care, a 5\% trimmed mean was calculated. This removes the lowest and highest $5 \%$ of cases from the analysis (i.e. the outliers). With regard to informal care costs, an alternative replacement cost method was used, whereby, each hour of informal care was valued using the HSE salary scale and associated non-pay costs of a health care assistant, which is $€ 30$ per hour (HSE, 2018). This method is viewed as being less conservative than the opportunity cost approach; which may lead to an underestimation of informal 
caregiving costs. For capital costs, instead of using a zero per cent discount rate in order to calculate the equivalent weekly housing cost over a 50 year period, discount rates of two percent and five percent were assumed respectively.

Following the removal of outliers, the 5\% trimmed mean for the average cost of IHCP support hours was $€ 775$ ( $€ 379$ - $€ 1,176)$, which remained almost unchanged from the full mean. With regard to private out-of-pocket expenditure on care, the average is reduced to $€ 245$ per week ( $€ 0-€ 2,332), € 146$ less than the full mean. When a replacement valuation is applied to informal care, costs quadruple to an average of $€ 2,389$ (€60 - €3,990) per week. Applying a discount rate of two percent, in order to calculate the equivalent annual housing cost over a 50 year period, increases the cost of capital to $€ 147$ per week. When a five percent discount rate is assumed, costs increase further to $€ 254$ per week.

\section{Discussion}

This study examined data from the HSE-Genio Dementia Programme on resource utilization of formal, informal and private care in order to analyze the cost of care for people living at home but on the boundary of residential care. The average weekly cost of community-based care, funded through public expenditure, and comprising of standard community-based provision and IHCPs is cheaper than residential care alternatives, especially public long-stay care settings - $€ 872$ per week compared to $€ 1,526$ per week. Including housing and personal consumption costs raised the cost of community-based care, but home care remains below public long-stay care facilities and around the same cost as private nursing homes in Dublin. 
The results suggest that even with increased public spending on IHCPs, significant informal care and, increasingly, private care are needed to keep people with dementia living at home rather than in residential care facilities (O'Shea \& Monaghan, 2016). If traditional community-based care is characterized by its absence in this study, family care is the opposite and is the main bulwark of care for people with dementia, as well as being a major contributor to costs. Informal care comprises $25 \%$ of the total cost of care. Adding family care inputs to care, valued using an opportunity cost methodology, raises the average cost of home care by $€ 593$ per week. Therefore, when measured from a societal perspective, home care may be more expensive than residential care, both public and private facilities. But then it is possible to see this differential as the price people are willing to pay to support home care over residential care (O’Shea, Gannon, \& Kennelly, 2008). Adding private outof-pocket expenditure on care further inflates the cost of home care.

However, it is important to consider that private out-of-pocket expenditure and informal care costs might also be incurred in a residential care setting. For example, the Irish DeStress study found that over half of caregivers whose spouse had moved into long-stay residential care visited their spouse every day (Brennan et al., 2017). Some carers continue to play an important caring role in the residential care setting where they offer emotional support, companionship and assistance with daily activities (Timonen, 2009). A recently published systematic literature review found that for people with dementia living in residential care facilities, informal care continued to be important (Boumans, Van Boekel, Baan \& Luijkx, 2018). But, whatever about comparisons with residential care, even with all costs accounted for, keeping people with dementia living in their own homes is less than half of the weekly cost of care in an acute hospital. 
Previous cost studies internationally have identified higher costs in institutional long-term care settings compared to formal, exchequer-funded community care provision. Data from a study involving eight European countries found that residential costs were higher than basic home care costs (Wübker et al., 2015). However, our results suggest that communitybased care can be just as expensive as residential care, and more, if we include informal care costs and private out-of-pocket expenditure on care. Similarly, Leicht et al. (2013) suggests that the societal cost of caring for people in the community can be considerably higher than nursing home costs if informal care is taken into account. Wübker et al. (2015) also found that home care costs are sensitive to the valuation of informal care, similar to our results and subsequent sensitivity analysis. This research also reflects previous cost estimates for people with dementia on the boundary between community and residential care in Ireland (O'Shea \& Monaghan, 2016), whereby, high family care costs were identified irrespective of the additional supports received.

From an international perspective, this research contributes to a growing field of research on the costs of care for people with dementia, and therefore contributes towards informing future health care service planning and provision for individuals with dementia living on the boundary between home care and residential care. There are, however, limitations to the present study. The sample size was small, making it possible that the results of the study are not generalizable to the wider dementia population. The results, therefore, should be viewed with caution, although Table 1 suggests that the sample is largely representative of the whole group of people with dementia who have received an IHCP in Ireland. In most cases, data on resource utilization was reported by caregivers giving rise to a possibility of bias, as this information was not validated by another source; it should also be 
acknowledged that difficulties in recall can occur in relation to resource use in the previous 30 days. Given that reliable data on costs in Ireland are generally limited, unit cost data for the vast majority of services had to be drawn from a variety of sources, including outside of the country. This is likely to have had a negative impact on the accuracy of some of the cost estimates.

Future research with more participants is required on resource utilization and costs of care associated with different care settings, both in Ireland and elsewhere. With regard to private out-of-pocket expenditure on care, it would be useful to gain an understanding of what types of resources are being purchased in the community setting. Also, predicting factors that influence admission to long-stay care or mortality would further enhance our understanding of the resource allocation process, as it would help focus policy attention on the key factors that can prolong living at home and extend life for dependent older people. The use of statistical methods such as survival analysis, which focuses on modelling time to event data, would also be useful from a policy viewpoint in order to consider both the rate and incidence associated with admission to long-stay care and/or mortality.

In conclusion, this study has shown that it is possible to increase the availability of publicly provided intensive home care supports to augment existing formal provision in the community and still cost the exchequer less than $60 \%$ of weekly public residential care costs. Investment in intensive supports for people with dementia is good value for money for the public sector, especially for people on the boundary between home care and residential care. New legislation currently going through the Irish parliament is intended to provide designated rights for home care in Ireland for the first time ever. It is not known yet what that will actually mean in terms of scale, provision and cost sharing. But there is 
evidence from Scotland that free personalized care, while expensive, may prevent even higher levels of cost inflation by keeping people out of residential facilities (Bell, Rutherford, Alasdair \& Wright, 2013). New investment in community-based care may also take some of the burden of care off family carers, even if the evidence of this study is that the latter still contribute significantly to care in the home. Additional public support may be necessary anyway in the future, as there may be fewer adult children available to help care for their elderly parents, should they become dependent. The growing importance of private out-of-pocket expenditure on care for some people should also be noted, particularly the potential for inequities to develop as that market evolves. What has been confirmed is that family care costs remain high even in the presence of IHCPs; what is emerging is the increase in private out-of-pocket payments for care. 


\section{Acknowledgements}

The authors would like to express their gratitude to the HSE-Genio Dementia Programme who supported this study and the people with dementia and caregivers who participated in the study.

\section{Funding}

This work was financially supported by Genio.

\section{Declaration of Conflicting Interests}

None declared. 


\section{References}

Argyle, E., Downs, M., \& Tasker, J. (2010). Continuing to care for people with dementia: Irish family carers' experience of their relative's transition to a nursing home. Bradford, Dublin and Cork: Bradford Dementia Group, The Alzheimer Society of Ireland and St Luke's Home.

Bell, D.N.F., Rutherford, A.G., \& Wright, R. (2013). Free personal care for older people: a wider perspective on its costs. Fraser of Allander Economic Commentary, 36, 69-76.

Boumans, J., Van Boekel., L.C., Baan, C.A., \& Luijkx, K.G. (2018). How can autonomy be maintained and informal care improved for people with dementia living in residential care facilities: a systematic literature review? Innovation in Ageing, 2, 1-22.

Brennan, S., Lawlor, B., Pertl, M. M., O’Sullivan, M., Begley, E., \& O’Connell, C. (2017). De-Stress: A study to assess health and well-being of spousal carers of people with dementia in Ireland. Dublin, Ireland: Alzheimer Society of Ireland.

Brick, A., Normand, C., O’Hara, S., \& Smith, S. (2015). Economic evaluation of palliative care in Ireland. Dublin, Ireland: Trinity College Dublin.

Browne, M. (2016). Responding to the supports and care needs of our older population. Dublin, Ireland: sage.

Central Statistics Office (2017). Earning and labour costs. Dublin, Ireland: Central Statistics Office. 
Central Statistics Office (2018). Inflation indices 2018. Dublin, Ireland: Central Statistics Office.

Challis, D., \& Hughes, J. (2003). Residential and nursing home care - issues of balance and quality of care. International Journal of Geriatric Psychiatry, 18, 201-204.

Challis, D., Tucker, S., Wilberforce, M., Brand, C., Abendstern, M., ...Bowns, I. (2014). National trends and local delivery in old age mental health services: towards an evidencebase: a mixed methodology study of the balance of care approach, community mental health teams and specialist mental health outreach to care homes. Programme Grants for Applied Research, 2, 1-480.

Connolly, S., \& O'Shea, E. (2015). The impact of dementia on length of stay in acute hospitals in Ireland. Dementia, 14, 650-658.

Connolly, S., Gillespie, P., O'Shea, E., Cahill, S., \& Pierce, M. (2014). Estimating the economic and social costs of dementia in Ireland. Dementia, 13, 5-22.

Department of Health and Children, (2001). Quality and Fairness: A Health System for You. Dublin, Ireland: Stationery Office.

Department of Health. (2014). The Irish National Dementia Strategy. Dublin, Ireland: Department of Health.

Department of Health. (2018). Support Older People to Lead Health Older Lives. Dublin, Ireland: Department of Health.

Department of the Taoiseach (2009). Revised RIA Guidelines: How to conduct a Regulatory Impact Analysis. Dublin, Ireland: Department of the Taoiseach. 
Dewing, J. (2008). Process consent and research with older persons living with dementia. Research Ethics, 4, 59-64.

Donnelly, S., O’Brien, M., Begley, E., \& Brennan, J. (2016). 'I'd prefer to stay at home but I don't have a choice': Meeting Older People's Preference for Care: Policy, but what about practice? Dublin, Ireland: University College Dublin.

Gillespie, P., O’Shea, E., Cullinan, J., Buchanan, J., Bobula, J., ...Lawlor, B. (2015). Longitudinal costs of caring for people with alzheimer's disease. International Psychogeriatrics, 27, 847-856.

Green, C., Richards, D. A., Hill, J. J., Gask, L., Lovell, K., Chew-Graham, C., ...Barkham, M. (2014). Cost-effectiveness of collaborative care for depression in UK primary care: economic evaluation of a randomized controlled trial (CADET). PLOS one, 9, 1-12.

Health Information and Quality Authority (2018). Guidelines for the budget impact analysis of health technologies in Ireland. Dublin, Ireland: Health Information and Quality Authority.

Health Service Executive (2018). List of Reimbursable Items. Retrieved from https://www.hse.ie/eng/staff/pcrs/online-services/.

Health Service Executive (2018). Pay scales; HSE, 2018. Retrieved from https://www.hse.ie/eng/staff/benefitsservices/pay/.

Health Service Executive (2018). Public Nursing Home Costs. Retrieved from https://www.hse.ie/eng/fair-deal-scheme/your-payment-towards-care/how-muchyou-will-need-to-pay/. 
Health Service Executive (2018). Response to parliamentary questions 6498/17. Retrieved from https://www.hse.ie/eng/about/personalpq/pq/.

Health Service Executive (2018). Voluntary and Private Nursing Home Costs. Retrieved from $\underline{\text { https://www.hse.ie/eng/fair-deal-scheme/your-payment-towards-care/how- }}$ much-you-will-need-to-pay/.

Health Service Executive (2018). What is dementia? Retrieved from http://www.understandtogether.ie/about-dementia/what-is-dementia.

Health Service Executive (2019). About the HSE - Who We Are, What We Do. Retrieved from https://www.hse.ie/eng/about/.

Hospital In-patient Enquiry. (2017). HIPE Data Requests. Dublin: Ireland.

Hospital In-patient Enquiry. (2015). HIPE Data Requests. Dublin: Ireland.

Howe, A. L., \& Kung, F. (2003). Does assessment make a difference for people with dementia: The effectiveness of the aged care assessment teams in Australia? International Journal of Geriatric Psychiatry, 18, 205-210.

Institute of Public Health. (2018). Improving home care services in Ireland: An overview of the findings of the department of health's public consultation. Dublin, Ireland: Institute of Public Health Ireland.

Keogh, F., Pierce, M., Neylon, K., Fleming, P., Carter, L., O’Neill, S., \& O’Shea, E. (2018). Supporting older people with complex needs at home: evaluation of HSE intensive home care package initiative. Dublin, Ireland: Genio. 
Keogh, F., Pierce, M., Neylon, K., Fleming, P., O’Neill, S., Carter, L., \& O’Shea, E. (2018). Supporting older people with complex needs at home: what works for people with dementia. Dublin, Ireland: Genio.

Knapp, M., Chisholm, D., Astin, J., Lelliott, P., \& Audini, B. (1997). The cost consequences of changing the hospital community balance: the mental health residential care study. Psychological Medicine, 27, 681-692.

Lafferty, A., Fealy, G., Downes, C., \& Drennan, J. (2014). Family carer's of older people: results of a national survey of stress, conflict and coping. Dublin, Ireland: University College Dublin and the Health Service Executive.

Leicht, H., Hans-Helmut, K., Stuhldreher, N., Bachmann, C., Bickel, H., Fuchs, A., ...Riedel-Heller, S. (2013). Predictors of costs in dementia in a longitudinal perspective. PLOS one, 8, 1-10.

Lyons, R. (2018). The Daft.ie house price report: an analysis of recent trends in the Irish residential sales market for 2017 in review. Dublin, Ireland: Daft.

National Centre for Pharmacoeconomics (2016). Guidelines for inclusion of drug costs in pharmacoeconomic evaluations. Dublin, Ireland: NCPE.

National Economic and Social Forum. (2005). Care for older people. Dublin, Ireland: NESF.

O’ Shea, E., Cahill, S., \& Pierce, M. (2017). Developing and implementing dementia policy in Ireland. Galway, Ireland: NUI Galway; Centre for Economics and Social Research on Dementia. 
O'Shea, E. (2017). The economics and financing of care for dependent older people in Ireland. Dublin, Ireland: Houses of the Oireachtas.

O'Shea, E., \& Carney, P. (2016). Dementia paying dividends: a report on the Atlantic philanthropies investment in dementia in Ireland. Galway, Ireland: NUI Galway; Centre for Economics and Social Research on Dementia.

O'Shea, E., \& Monaghan, C. (2016). An economic analysis of community- based model for dementia care in Ireland: a balance of care approach. Galway, Ireland: NUI Galway; Centre for Economics and Social Research on Dementia.

O’Shea, E., \& Monaghan, C. (2017). An economic analysis of a community-based model for dementia care in Ireland: a balance of care approach. International Psychogeriatrics, $29,1175-1184$.

O’Shea, E., Gannon, B., \& Kennelly, B. (2008). Eliciting preferences for resource allocation in mental health care in Ireland. Health Policy, 88, 359-370.

OECD (2018). Purchasing Power Parities Data 2017. Paris: OECD. Retrieved from http://www.oecd.org/std/prices-ppp/.

Office for National Statistics (2018). Consumer Price Inflation Health 2015=100 excel sheet. London: Office for National Statistics. Retrieved from: https://www.ons.gov.uk/economy/inflationandpriceindices.

Office.

Pierse, T., O'Shea, E., \& Carney, P. (2018). Estimates of the prevalence, incidence and severity of dementia in Ireland. Irish Journal of Psychological Medicine, 36, 1-9. 
Prince, M., Wimo, A., Guerchet, M., Claire-Ali, G., Wu, Y.T., \& Prina, M. (2015). World Alzheimer report 2015, the global impact of dementia, an analysis of prevalence, incidence, costs and trends. London, UK: Alzheimer's Diseases International.

Robins, J. (1988). The years ahead: a policy for the elderly: Report of the Working Party on Services for the Elderly. Dublin, Ireland: Health Service Executive.

Rothera, I., Jones, R., Harwood, R., Avery, A.J., Fisher, K., James, V., ...Waite, J. (2008). An evaluation of a specialist multiagency home support service for older people with dementia using qualitative methods. International Journal of Geriatric Psychiatry, 23, 6572.

Spijker, A., Vernooij-Dassen, M., Vasse, E., Adang, E., Wollersheim, H., Grol, R., \& Verhey, F. (2008). Effectiveness of nonpharmacological interventions in delaying the institutionalization of patients with dementia: a meta-analysis. Journal of the American Geriatrics Society, 56, 1116-1128.

Timonen, V. (2009). Toward an integrative theory of care: formal and informal intersections. In K.A. Roberto (Ed.), \& J.A. Mancini (Ed.), Human Development and the lifespan: antecedents, processes and consequences of change (pp.1-25). Maryland: Lanham, MD: Lexington.

Timoney, A. (2018). Home care for older people - seven policy changes. Dublin, Ireland: Houses of the Oireachtas.

Toot, S., Swinson, T., Devine, M., Challis, D., \& Orrell, M. (2017). Causes of nursing home placement for older people with dementia: a systematic review and meta-analysis. International Psychogeriatrics, 29, 195-208. 
Tucker, S., Sutcliffe, C., Bowns, I., Challis, D., Saks, K., Verbeek, H., ...Soto, M.E. (2016). Improving the mix of institutional and community care for older people with dementia, an application of the balance of care in eight European countries. Aging \& Mental Health, 20, 1327-1338.

Wren, M-A., Keegan, C., Walsh, B., Bergin, A., Eighan, J., Brick, A., ...Banks, J. (2017). Projections of Demand for Healthcare in Ireland 2015-2030. Dublin, Ireland: Economic and Social Research Institute.

Wübker, A., Zwakhalen, S.M., Challis, D., Suhonen, R., Karlsson, S., Zabalequi, A., ...Sauerland, D. (2015). Costs of care for people with dementia just before and after nursing home placement: primary data from eight European countries. The European Journal of Health Economics, 16, 689. 